Research Article

\title{
Elimination of Coal and Gas Outburst Dynamic Disasters in Dengfeng Coalfield through Gas Extraction Based on Extremely Thin Protective Coal Seam Mining
}

\author{
Haibo Liu $\mathbb{D}^{\mathrm{D}}$, Xucheng Xiao, and Zhihang Shu \\ School of Safety Engineering, China University of Mining and Technology (CUMT), Xuzhou 221116, China \\ Correspondence should be addressed to Haibo Liu; liuhaibo-8888@163.com
}

Received 25 April 2021; Revised 18 June 2021; Accepted 31 August 2021; Published 16 September 2021

Academic Editor: Juan Sagaseta Sagaseta

Copyright (c) 2021 Haibo Liu et al. This is an open access article distributed under the Creative Commons Attribution License, which permits unrestricted use, distribution, and reproduction in any medium, provided the original work is properly cited.

\begin{abstract}
No. $2_{1}$ coal seam is a full-thickness structured soft coal in Dengfeng coalfield. The coal seam gas-bearing capacity is high, and the permeability is poor, thus resulting in serious coal and gas outburst dynamic disasters. According to the gas geological conditions of Baoyushan Mine, No. $1_{7}$ coal seam without outburst danger, which is $0.5 \mathrm{~m}$ thick and $23.4 \mathrm{~m}$ under No. $2_{1}$ coal seam, was mined in advance as the lower protective seam. At the same time, a gas extraction roadway was constructed in No. $2_{1}$ coal seam floor. Cross-layer boreholes were constructed to extract the pressure relief gas of No. $2_{1}$ coal seam for comprehensive treatment of mine gas. The mobile deformation of the overburden coal and rock mass after mining No. $1_{7}$ coal seam, the fracture development characteristics of No. $2_{1}$ coal seam, the pressure relief gas migration of the coal seam, the gas extraction, and the outburst danger elimination were studied. The research findings showed the following: (1) after mining No. $1_{7}$ coal seam, the overburden hard and extremely thick limestone roof sagged slowly, albeit leading to no craving zone. (2) The permeability of No. $2_{1}$ coal seam was increased by about 394 times, from $0.0012 \mathrm{mD}$ to $0.4732 \mathrm{mD}$. (3) After the extraction of pressure relief gas through the gas extraction roadway on the floor through the cross-layer borehole, the gas pressure of No. $2_{1}$ coal seam decreased from $1.17 \mathrm{MPa}$ to $0.12 \mathrm{MPa}$, while the gas content decreased from $9.74 \mathrm{~m}^{3} / \mathrm{t}$ to $3.1 \mathrm{~m}^{3} / \mathrm{t}$, which suggested that the coal and gas outburst dynamic danger of No. $2_{1}$ coal seam was totally eliminated and the goal of safe and efficient mining in the mine was realized.
\end{abstract}

\section{Introduction}

Coal is the major energy of China, which accounts for more than $60 \%$ of the primary energy $[1,2]$. With the rapid development of Chinese economy, the coal demand also increased dramatically. From 2001 to 2020, China's coal output soared from 1.106 billion tons to 3.7 billion tons. Limited by the conditions of coal resources, $90 \%$ of coal resources are obtained through underground mining. The mining depth of coal increases at an annual rate of $10 \sim 30 \mathrm{~m}$. Currently, the average mining depth of the coal resources in China has exceeded $600 \mathrm{~m}$, with the deepest one exceeding $1,500 \mathrm{~m}$. With the intensification of coal mining, the mining depth keeps on increasing, resulting in growing ground stress on the working seam, increasing coal seam gas pressure and gas emission amount, and increasing complexity and danger of gas disasters [3]. Many low gas mines have been turned into high gas ones, and the high gas ones have been turned into coal and gas outburst ones. In China, the coal mines had a tendency to increase gas grade and increase the number of outburst mines. In particular, the mines in central China are characterized by in-depth mining, high coal seam gas content, high gas pressure, complex geographical conditions, and soft and crushed coal seam structure, so the coal mines are faced with serious gas disasters [4-7].

Located in about $60 \mathrm{~km}$ southwest of Zhengzhou, Henan Province, Dengfeng coalfield is about $70 \mathrm{~km}$ long and $8 \sim 15 \mathrm{~km}$ wide and covers an area of about $1,000 \mathrm{~km}^{2}$. The coalfield stratum can be divided into Permian System Shanxi Group and Taiyuan Group. No. 2 1 coal seam under the bottom of Shanxi Group is stable. It is the major minable coal seam of the coalfield. No. $2_{1}$ coal seam features a thickness of about $0 \sim 26.73 \mathrm{~m}$ and an average thickness of 
$4.57 \mathrm{~m}$. Thus, it is a medium-thickness coal seam. The coal rank is the meager coal. Affected by the extrusion, rubbing, and other tectonic movements, No. $2_{1}$ coal seam is characterized by full-thickness constructed soft coal. Most coals are of types III $\sim$ V. The coal strength and permeability are extremely low, the coal seam gas content is high, and the coal seam gas extraction effect is poor. Thus, the gas disasters are extremely serious. For a long time, the gas disasters of No. $2_{1}$ coal seam in Dengfeng coalfield, especially the coal and gas outburst disasters, have greatly limited the development of the local coal mine enterprises and seriously threatened the safety of miners. In order to ensure the mining safety of No. $2{ }_{1}$ coal seam in the deep area of the mine, the regional outburst prevention measures should be adopted to eliminate the coal and gas outburst dynamic disasters of No. $2_{1}$ coal seam.

Many mines in China have achieved remarkable results by adopting the measure of protective coal seam mining to prevent and control coal and gas outburst dynamic disasters [8-11]. Concerning the gas geological conditions of No. $2_{1}$ coal seam of Dengfeng coalfield, the adoption of protective seam mining combined with stress-relief gas extraction technique is the most effective, simplest, and most economic measure to prevent the coal and gas outburst disasters [12-16]. The technique can eliminate the coal and gas outburst dynamic disasters and finally realize the goal of safe and efficient mining. However, mines adopting the measure must be equipped with the condition of coal seam group occurrence. In other words, within the effective protection vertical interval, there should be a coal seam free of outburst danger whose thickness is no smaller than $0.5 \mathrm{~m}$ acting as the protective seam. According to the geological data of Dengfeng coalfield, the gas content of No. $1_{7}$ coal seam, which is $23.4 \mathrm{~m}$ below No. $2_{1}$ coal seam and whose thickness averages $0.5 \mathrm{~m}$, is extremely low, so it is the coal seam free of outburst danger and can be first mined as the lower protective seam. At the same time, the adoption of the gas extraction roadway during the construction in the chassis of No. $2_{1}$ coal seam and the extraction of the pressure relief gas of No. $2_{1}$ coal seam in the cross-layer boreholes can eliminate the coal and gas outburst dynamic disasters. However, there is a layer of $7.3 \mathrm{~m}$ thick hard limestone between No. $1_{7}$ coal seam and No. $2_{1}$ coal seam, which is unfavorable to the pressure relief and permeability increase effect of No. $2_{1}$ coal seam. Therefore, under the condition, it is necessary to conduct an experiment and field study to see whether the technique of mining extremely thin No. $1_{7}$ coal seam combined with the pressure relief gas extraction technique can eliminate the coal and gas outburst dynamic dangers of No. $2_{1}$ coal seam. The Baoyushan Mine in Dengfeng coalfield was adopted as the research object. Through the experiment and field test, the gas parameters of No. $2_{1}$ coal seam were obtained, and the outburst danger was analyzed. Through studying the overburden coal-rock mass displacement and distortion, the mining fracture development characteristics of No. $2_{1}$ coal seam, and the coal seam pressure relief gas migration and convergence rules, the authors hope that the research findings can guide Baoyushan Mine to conduct site protective seam mining. The research of the extremely thin protective seam mining combined with the pressure relief gas extraction under the hard and extremely thick limestone condition is the first of its kind. The research findings are of vital significance to the prevention and control of coal and gas outburst dynamic disasters during the in-depth mining of No. $2_{1}$ coal seam in Dengfeng coalfield.

\section{Geological Background}

Baoyushan Mine is located in the westmost Dengfeng coalfield and the junction of Ruyang County, Linru County, and Yichuan County. It is about $100 \mathrm{~km}$ away from Zhengzhou City, capital city of Henan Province. Its geographical coordinates are $112^{\circ} 34^{\prime} 37.4^{\prime \prime} \sim 112^{\circ} 41^{\prime}$ east longitude and $34^{\circ} 18^{\prime} 02.4^{\prime \prime} \sim 34^{\circ} 21^{\prime} 54.4^{\prime \prime}$ north altitude. Its traffic situation is shown in Figure 1. The mine is about $5 \sim 11 \mathrm{~km}$ long and $1.1 \sim 3.0 \mathrm{~km}$ wide and covers an area of $21.2186 \mathrm{~km}^{2}$. It is a coal and gas outburst mine with a design production capacity of 600,000 ton per annum. No. $2_{1}$ coal seam is the major mining area of the mine.

The mine adopts the inclined shaft and the vertical shaft mixed exploitation method, the full-seam mining method, and the fully caving roof management. There are two major minable coal seams, namely, No. $2_{1}$ coal seam and No. $1_{7}$ coal seam. The composite histogram of the mine is shown in Figure 2. No. $2_{1}$ coal seam is about $0 \sim 18.98 \mathrm{~m}$ thick, which is averaged at $3.1 \mathrm{~m}$. The coal bed pitch is $30^{\circ}$. The gas content of No. $2_{1}$ coal seam is high. The gas content is above $8 \mathrm{~m}^{3} / \mathrm{t}$. The mine mainly treats the gas outbursts through the drainage borehole, bleeder off hole, and increase of the wind amount for the mining working face. However, due to high gas content of No. $2_{1}$ coal seam, the coal seam is soft and has poor permeability. As a result, the gas extraction effect is poor. During the mining process, the gas density in the ventilation roadway often exceeds the limit, which seriously threatens the safe production of the mine. Even if the wind amount for the working face is increased to above $1,000 \mathrm{~m}^{3} /$ min, the problem still remains unresolved. During the blasting process, the gas exceeds the limit more seriously. At the same time, due to the large wind amount for the working face, the working face is filled with the coal dust, thus worsening the working environment of miners. It is apt to say that gas disasters directly restrain the safe and efficient production of the mine.

In order to solve the difficulties facing the prevention and control of gas disaster, based on Detailed Rules of Coal and Gas Outburst Prevention and Control and the conditions of the coal seam, the authors decided to adopt the protective seam mining combined with pressure relief gas extraction technique. No. $1_{7}$ coal seam of the mine was adopted as the lower protective seam for prior mining. At the same time, the gas extraction roadway was placed in the proper position of the chassis of No. $2_{1}$ coal seam. The pressure relief gas was extracted from No. $2_{1}$ coal seam through the boreholes. The thickness of No. $1_{7}$ coal seam in Baoyushan Mine is about $0.12 \sim 1.1 \mathrm{~m}$, which averages $0.5 \mathrm{~m}$. It belongs to the extremely thin coal seam and the coal seam gas content is low, which is about $0.5 \sim 1.5 \mathrm{~m}^{3} / \mathrm{t}$, so No. $1_{7}$ coal seam has no outburst danger. No. $1_{7}$ coal seam is mined 


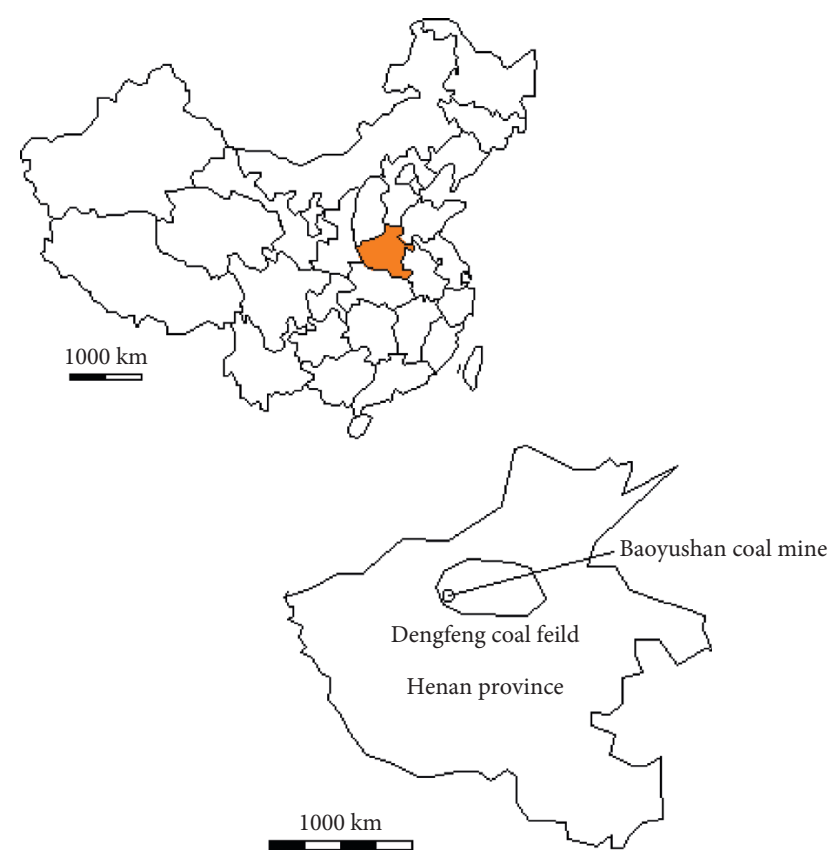

FIGURE 1: Maps showing the traffic situation of the study area. (It is reproduced from [17].)

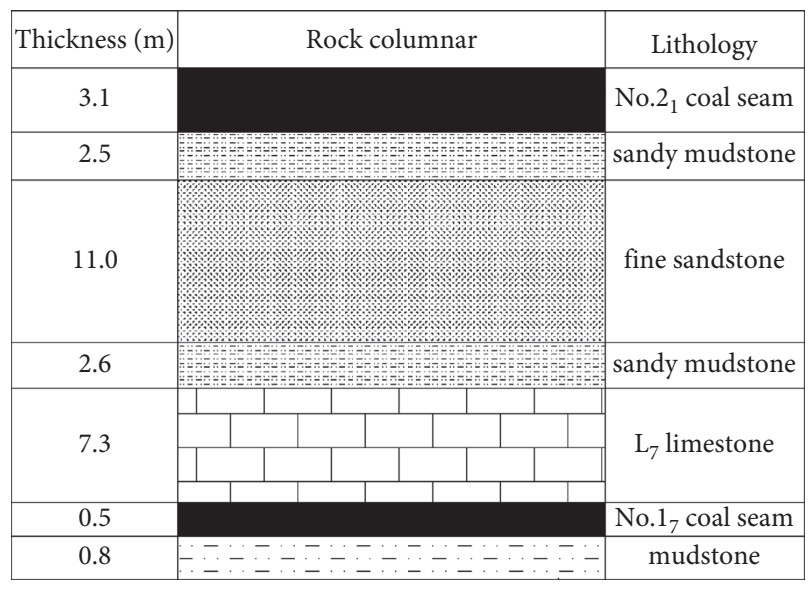

Figure 2: The composite histogram of Baoyushan Mine.

using spiral drilling machine and adopts the gradual sagging method to manage the roof [17]. The average mining height of No. $1_{7}$ coal seam is $0.5 \mathrm{~m}$.

\section{Parametric Measurement and Outburst Danger Evaluation of No. 2, Coal Seam}

\subsection{Parametric Measurement of No. $2_{1}$ Coal Seam}

3.1.1. Industrial Analysis and Absorption Performance Experiment Results. The coal absorption performance experiment was based on the coal's gas absorption theory. Generally speaking, the absorption constants, $a$ and $b$, are the two indexes evaluating the coal's gas absorption performance. The measurement of coal's gas absorption constants was conducted in the lab according to the national standard, Measurement Method of Coal's Gas Absorption Amount. First, the sample of No. $2_{1}$ coal seam was obtained from Baoyushan Mine. Using the HCA high-pressure volume method, the gas absorption experiment devices, and 5E-MAG6600 full-automatic industrial analyzer, the gas absorption constants, moisture, ash content, and volatile components of No. $2_{1}$ coal seam were measured, respectively. The experiment devices are shown in Figure 3. The actually measured value of $a$, an absorption constant of No. $2_{1}$ coal seam, was $28.834 \mathrm{~m}^{3} / \mathrm{t}$; the actually measured value of $b$, the other absorption constant, was $0.835 \mathrm{MPa}^{-1}$; the moisture of No. $2_{1}$ coal seam was $1.12 \%$; the ash content was $8.98 \%$; and the volatile components were $13.03 \%$.

The coal's porosity refers to the ratio of the bulk volume of the hole to the bulk volume of the coal. This index decides the absorbability, permeability, and strength of coal and the gas migration characteristics within the coal. The porosity of No. $2_{1}$ coal was calculated through the actually measured true and false proportion of No. $2_{1}$ coal sample. The result showed that the porosity of No. $2_{1}$ coal was $2.82 \%$.

3.1.2. Coal Structure, Gas Diffusion Initial Velocity, and Firmness Coefficient. Detailed Rules of Coal and Gas Outburst Prevention and Control clearly divides the coal destruction types into five. I and II are the nontectonic coal without outburst dangers. III, IV, and V coal are the tectonic coal; they are basically corresponding to the tectonically crashed coal, the fractionalized coal, and the mylonitic coal. The site observation of No. $2_{1}$ coal seam in Baoyushan Mine shows that No. $2_{1}$ coal seam has the following characteristics: the coal mass is mainly powdery and seldom granulous or flaky. It lacks luster and has no bedding. Its strength is low and can be twiddled into powder by hand. The protogenesis structure of the coal has been seriously damaged. The lump coal formed through press of the pulverized coal is mixed in the coal mass now and then. The strength is low, and it can be fragmented by the press of a finger. It belongs to the fullthickness tectonic coal, and the destruction type of its coal mass belongs to IV-V coal.

The WT-1 gas diffusion rate tester and the coal firmness coefficient tester were employed to test the gas diffusion initial velocity and the coal firmness coefficient of No. $2_{1}$ coal seam. The experiment devices are shown in Figure 3. The actually measured gas initial velocity of No. $2_{1}$ coal seam in Baoyushan Mine was $12 \sim 27 \mathrm{mmHg}$, and the firmness coefficient of the coal mass was $0.1 \sim 0.18$.

3.1.3. Gas Pressure and Gas Content of No. 2 $2_{1}$ Coal Seam. Seam gas pressure refers to the acting force generated by the free thermal motion of the gas molecules within the hole of the coal seam, namely, the gas pressure exerted on the hole wall. The gas pressure of the coal seam is an important index to evaluate the outburst danger and the gas content of the coal seam [18]. At the same time, the gas pressure is also the basic parameter which decides the gas migration power and the potential of gas power. It plays a guiding role in the research and evaluation of gas emission, gas migration, gas extraction, and gas outburst [13, 19-22]. 


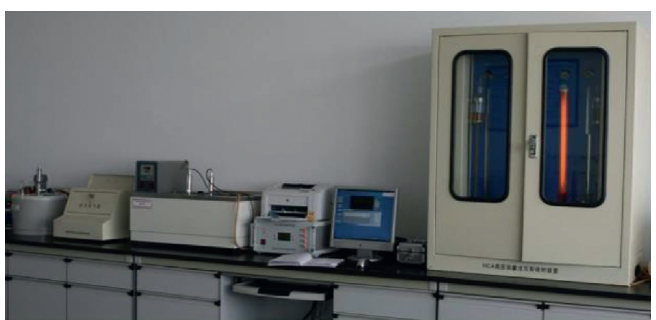

(a)

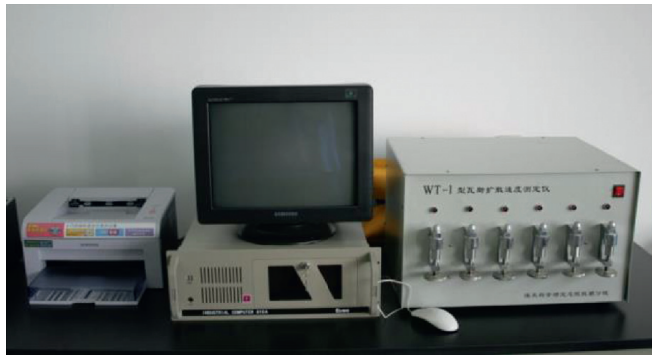

(c)

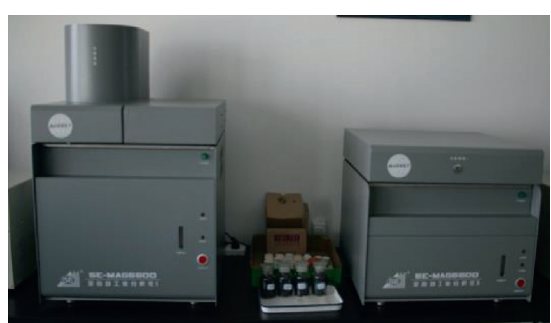

(b)

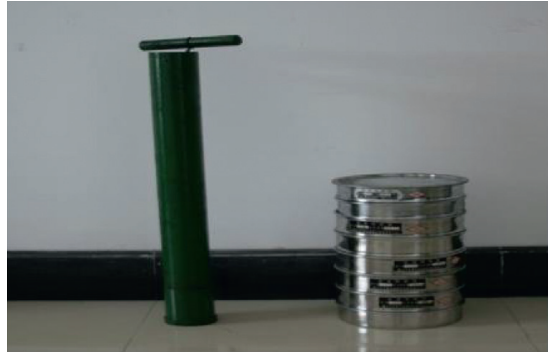

(d)

FIGURE 3: Instruments used in the determination of coal seam gas parameters: (a) gas absorption experiment device; (b) 5E-MAG6600 fullautomatic industrial analyzer; (c) WT-1 gas diffusion rate tester; (d) coal firmness coefficient tester.

According to the requirements of direct measurement methods of the gas pressure of the coal seam under the coal mine, slip casting and hole sealing pressure measurement method was adopted to test the gas pressure of No. $2_{1}$ coal seam in Baoyushan Mine. The piezometer tube with the holder was installed to the predetermined pressure depth under the mine. The porthole was sealed with the chuck and the quick-drying cement. The slip casting tube was installed. The use amount of the puff and nonshrink cement was determined by the depth of hole sealing. The hole sealing cement paste was prepared according to certain proportion (water-cement ratio was $2: 1$; the mixing amount of the swelling agent was $12 \%$ of the cement). The hole sealing cement paste was continuously injected into the borehole at once with the injection pump. After the slip casting lasted for $24 \mathrm{~h}$, the triple-channel devices and the piezometer were installed in the porthole. Based on the natural permeation principle of gas in No. $2_{1}$ coal seam, the gas pressure to achieve the balance in the borehole disclosed area was tested (see Figure 4). The site's actually tested gas pressure of No. $2_{1}$ coal seam in Baoyushan Mine was $1.17 \mathrm{MPa}$.

The coal seam gas content refers to the gas content in the unit mass or volume of the original coal mass. According to the requirements of direct measurement methods of the gas pressure of the coal seam under the coal mine, a hole was drilled in Baoyushan Mine. Through hole drilling, No. $2_{1}$ sample coal was fetched from the in-depth coal seam and was sealed in the bottle immediately. The field test of the gas desorption amount lasted for two hours. According to the gas desorption rule of the coal sample, the gas loss amount before the gas was sealed in the coal sample bottle was deducted. Then, the coal sample bottle was taken to the lab to conduct the remaining gas content test. The test devices are shown in Figure 5. The coal seam gas content is the sum of the gas loss amount, gas desorption amount, and remaining

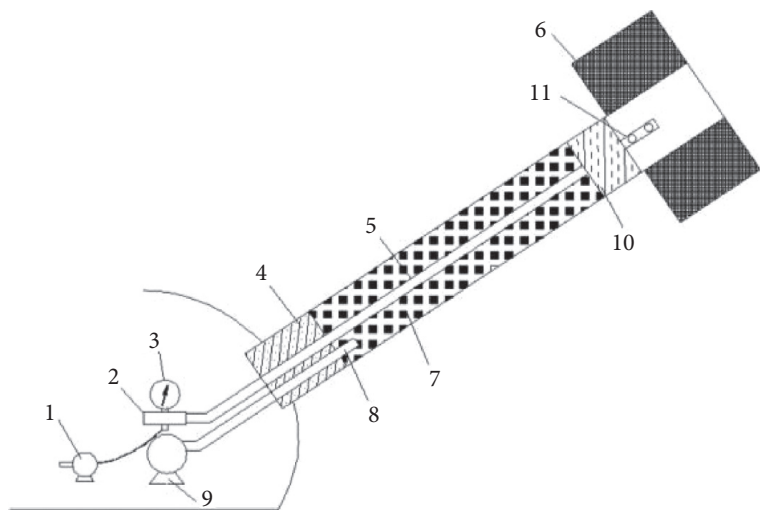

FIgURE 4: Schematic diagram of coal seam gas pressure grouting method: (1) air charging system; (2) three direct links; (3) pressure gage; (4) wooden wedge; (5) piezometer tube; (6) coal seam; (7) blocking material; (8) injection pipe; (9) grouting pump; (10) holder; (11) small holes.

gas amount. The actually measured gas content of No. $2_{1}$ coal seam of Baoyushan Mine was $9.74 \mathrm{~m}^{3} / \mathrm{t}$.

\subsection{Analysis of the Outburst Danger of No. $2_{1}$ Coal Seam}

3.2.1. Coal and Gas Outburst Disasters of No. $2_{1}$ Coal Seam of the Adjacent Coal Mines. The coal mines which focus on mining the shallow part of No. $2_{1}$ coal seam and which are adjacent to the Baoyushan Mine include Pochi Mine, Poxin Mine, Lugou No. 8 Mine, and Lugou Mine. The coal mine adjacent to Baoyushan Mine in the east is Hezhuang Mine and in the west Changhong Mine. The coal mines which focus on mining the shallow include Shangzhuang Mine and Baoyushan No. 2 Mine. The relative position relationship of coal mines adjacent to Baoyushan Mine is shown in Figure 6. 


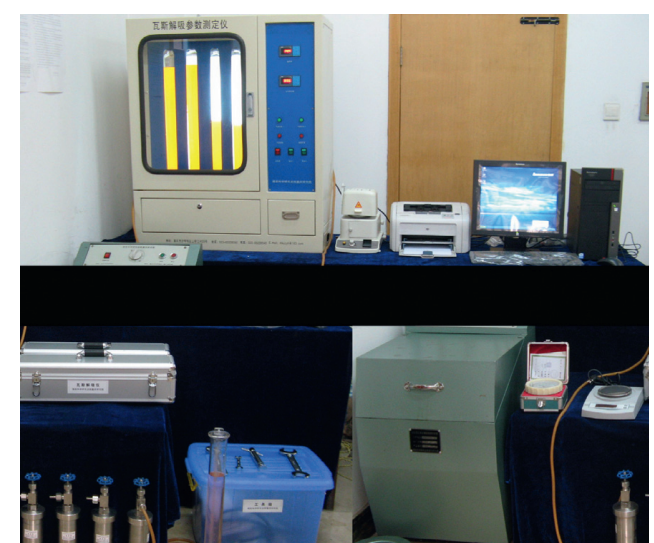

FIgURE 5: Coal seam gas content measurement instrument.

According to the investigation, the gas dynamic phenomenon of the adjacent mines is shown as follows: Pochi Mine, Poxin Mine, Lugou No. 8 Mine, and Lugou Mine are the coal mines which mined the shallow part of No. $2_{1}$ coal seam. During the mining period, the coal seam gas emission is low. In recent years, the gas grade has been identified as the low level. No coal and gas outburst dynamic phenomena have ever happened.

Shangzhuang Mine is located in the shallow part of Changhong Mine. In February 1977, there was a gas explosion accident. Two persons died and 17 were burned. In August 1981, gas combustion occurred, leading to the death of one person. It has ceased production.

Baoyushan No. 2 Mine is located in the shallow part of Changhong Mine and in the west of Shangzhuang Mine. On September 5, 2000, in $+250 \mathrm{~m}$ horizontal transportation avenue, an extremely serious coal and gas outburst happened, leading to the death of 14 persons and the injury of 8 persons. On November 21, 2001, a gas stifling accident caused the death of two. Now, it has ceased production.

Hezhuang Mine and Baoyushan Mine are not connected with each other but are close to each other. The gas dynamic phenomena happened here several times. In 2007, it was identified as coal and gas outburst mine. On April 8, 2009, in the 11030 Transportation Avenue, a medium-size coal and gas outburst happened. The outburst coal and rock amount was $215 \mathrm{t}$ and that of the gas amount was $10,089 \mathrm{~m}^{3}$.

Changhong Mine is connected with the west part of Baoyushan Mine. On October 16, 2004, during the tunneling process of the roadway on No. $2_{1}$ coal seam, a coal and gas outburst happened. The sound of coal blasting lasted for a long time, and the gas emission was abnormal. The gas concentration rose to $1.69 \%$ within a short time. The outburst coal amount reached about $13 \mathrm{t}$, and the outburst gas was about $500 \mathrm{~m}^{3}$. The actually measured gas content near the outburst point when the outburst happened was $5.34 \mathrm{~m}^{3}$ / t. In 2008, it was identified as the coal and gas outburst coal mine. On March 21, 2014, during the tunneling face of the roadway in Changhong Mine, a serious coal and gas outburst happened, leading to the death of 13 persons.
3.2.2. Gas Outburst Parameters and Outburst Danger Evaluation of No. $2_{1}$ Coal Seam. The actually measured gas outburst parameters of No. $2_{1}$ coal seam in Baoyushan Mine are shown in Table 1.

From Table 1, the following can be seen: (1) the gas pressure and gas content of No. $2_{1}$ coal seam in Baoyushan Mine were high. Gas pressure was $1.17 \mathrm{MPa}$, which was higher than the critical value, $0.74 \mathrm{MPa}$, specified in Detailed Rules of Coal and Gas Outburst Prevention and Control. Gas content was $9.74 \mathrm{~m}^{3} / \mathrm{t}$, which was higher than the critical value of $8 \mathrm{~m}^{3} / \mathrm{t}$ specified in Detailed Rules of Coal and Gas Outburst Prevention and Control and was far higher than that of No. $2_{1}$ coal seam in the outburst point of Changhong Mine, which was $5.34 \mathrm{~m}^{3} / \mathrm{t}$. (2) The initial velocity of gas emission of No. $2_{1}$ coal seam was $12 \sim 27 \mathrm{mmHg}$, which was higher than the critical value of $10 \mathrm{mmHg}$. (3) The coal mass structure of No. $2_{1}$ coal seam features the pulverized coal, which was a full-thickness tectonic soft coal. The protogenesis structure of the coal seam suffered serious damage, and the strength is extremely low. The firmness coefficient of No. $2_{1}$ coal seam was $0.1 \sim 0.18$, and the destruction type is $\mathrm{V}$. The original permeability of No. $2_{1}$ coal seam was 0.0012 $\mathrm{mD}$, so the seam permeability is extremely poor. The gas outburst parameters of No. $2_{1}$ coal seam in Baoyushan Mine are far higher than the outburst critical indexes specified in Detailed Rules of Coal and Gas Outburst Prevention and Control, so the outburst danger is high. No. $2_{1}$ coal seam of the adjacent coal mines underwent several coal and gas outbursts. To sum up, No. $2_{1}$ coal seam of Baoyushan Mine is a low permeability high gas outburst coal seam.

\section{Feasibility Analysis and Outburst Elimination Principle of the Extremely Thin Protective Seam Mining Combined with the Pressure Relief Gas Extraction Technique}

Since No. $2_{1}$ coal seam is characterized by strong outburst danger, we decided to adopt the protective seam mining combined with the pressure relief gas extraction technique to eliminate the coal seam outburst danger. According to the protective coal seam mining theory, the feasibility analysis of No. $1_{7}$ coal seam acting as the lower protective seam was first conducted.

\subsection{Feasibility Analysis of the Extremely Thin Protective Seam Mining}

4.1.1. The Minimum Interlayer Spacing for the Lower Protective Layer Mining. According to the requirements of Detailed Rules of Coal and Gas Outburst Prevention and Control, during the lower protective seam mining, the minimum interlayer spacing not ruining the upper protective seam could be defined through the following formula: $\alpha<60^{\circ}$ in the formula $H=K M \cos \alpha$, where $H$ stands for the minimum interlayer spacing of the minable protective seam, $M$ stands for the mining thickness of the protective seam and is set to be $0.5 \mathrm{~m}, \alpha$ stands for the coal bed pitch and is set to be $30^{\circ}$, and $\mathrm{K}$ stands for the roof management 

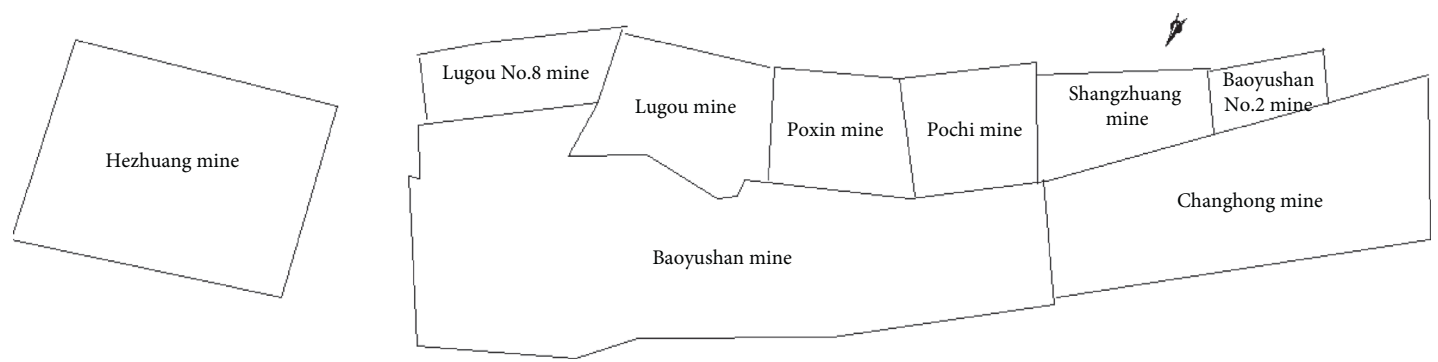

Figure 6: The relative position relationship of coal mines adjacent to Baoyushan Mine.

TABLE 1: Gas outburst parameters of No. $2_{1}$ coal seam.

\begin{tabular}{|c|c|c|c|c|}
\hline Gas outburst parameters & $\begin{array}{l}\text { Measured } \\
\text { value }\end{array}$ & $\begin{array}{l}\text { Detailed Rules of Coal and Gas } \\
\text { Outburst Prevention and Control }\end{array}$ & $\begin{array}{c}\text { Overweight (yes } \\
\text { or no) }\end{array}$ & Conclusion \\
\hline Gas pressure $(\mathrm{MPa})$ & 1.17 & 0.74 & \multirow{5}{*}{ Yes } & \multirow{5}{*}{$\begin{array}{c}\text { No. } 2_{1} \text { coal seam has serious } \\
\text { outburst danger }\end{array}$} \\
\hline Gas content $\left(\mathrm{m}^{3} / \mathrm{t}\right)$ & 9.74 & 8 & & \\
\hline Damage type of coal & IV, V & III, IV, V & & \\
\hline $\begin{array}{l}\text { Initial speed of gas diffusion } \\
(\mathrm{mmHg})\end{array}$ & $12 \sim 27$ & 10 & & \\
\hline Solidity factor & $0.1 \sim 0.18$ & 0.5 & & \\
\hline
\end{tabular}

Dynamic phenomenon of

mine gas disasters

No. $2_{1}$ coal seam in the adjacent mines has experienced many coal and gas outburst accidents.

coefficient; when the caving method is adopted to manage the roof, $K$ is set as 10 .

Through calculation, the minimum interlayer spacing, $\mathrm{H}$, for mining No. $1_{7}$ coal seam without damaging the upper No. $2_{1}$ coal seam, was $4.3 \mathrm{~m}$, which was smaller than $23.4 \mathrm{~m}$, the interlayer spacing between No. $1_{7}$ coal seam and No. $2_{1}$ coal seam. Thus, the requirement was met.

4.1.2. The Maximum Protection Vertical Distance for the Lower Protective Layer Mining. The maximum protection vertical distance for the lower protective layer mining, $S$, was calculated according to the requirement of Detailed Rules of Coal and Gas Outburst Prevention and Control: $S=S_{\text {lower }} \beta_{1} \beta_{2}$. In the formula, $S_{\text {lower }}$ stands for the maximum protection vertical distance of the protective seam, $m$. It is related to the working face length, $L$, and the mining depth, $H$. According to Detailed Rules of Coal and Gas Outburst Prevention and Control about $S_{\text {lower }}$, the following can be found: (1) When the working face depth and length of No. $1_{7}$ coal seam are $400 \mathrm{~m}$ and $125 \mathrm{~m}$, respectively, $S_{\text {lower }}$ is $66 \mathrm{~m}$. (2) $\beta_{1}$ stands for the influence coefficient of the protective seam mining, $\beta_{1}=M / M_{0}$, in which $M$ stands for the mining depth of the protective seam, $m$. (3) $M_{0}$ stands for the minimum valid thickness of the protective seam mining, $m$. (4) The average thickness of No. $1_{7}$ coal seam is $0.5 \mathrm{~m}$, and the minimum mining depth is $0.5 \mathrm{~m}$; then $\beta_{1}=1$. (5) $\beta_{2}$ stands for the coefficient of the interlayer hard rock. Considering that there is a $7.3 \mathrm{~m}$ thick hard limestone above No. $1_{7}$ coal seam, $\beta_{2}$ is set to be 1 and $S=S_{\text {lower }} \beta_{1} \beta_{2}=66 \mathrm{~m}$.

Like the lower protective seam mining of No. $2_{1}$ coal seam, No. $1_{7}$ coal seam has a maximum valid protection distance of $66 \mathrm{~m}$ and a minimum protection distance of $4.3 \mathrm{~m}$. The interlayer spacing between No. $1_{7}$ coal seam and
No. $2_{1}$ coal seam is $23.4 \mathrm{~m}$. Thus, it meets the requirement of the maximum protection seam spacing and the minimum protection distance, and it is a very ideal lower protection seam.

Therefore, the method of adopting No. $1_{7}$ coal seam as the lower protective seam mining to protect the upper No. $2_{1}$ coal seam and extracting the pressure relief gas in No. $2_{1}$ coal seam through drilling holes in the roadway is feasible.

\subsubsection{The Slanted Direction and Trend Protection Scope of the} Lower Protective Seam Mining. The protection range on the slanted direction of the lower protective seam mining was decided according to the pressure relief angle of $\delta$, specified in Detailed Rules of Coal and Gas Outburst Prevention and Control. Through the field test, the pressure relief angle on the slanted direction of No. $1_{7}$ coal seam was $\delta_{1}=71^{\circ}$ and $\delta_{2}=89^{\circ}$ (see Figure 7). When the slanted mining length of the working face of No. $2_{1}$ coal seam is designed to be $120 \mathrm{~m}$, the mining length of No. $1_{7}$ coal seam should be calculated according to the following formula: $L=120+23.4 / \tan 71^{\circ}+23.4 / \tan 89^{\circ}=128.5 \mathrm{~m}$. Thus, when the slanted length of the working face of No. $2_{1}$ coal seam is $120 \mathrm{~m}$, the slanted length of the working face of No. $1_{7}$ coal seam must be larger than $128.5 \mathrm{~m}$.

Through the field test, the mining pressure relief angle of No. $1_{7}$ coal seam along its trend direction in Baoyushan Mine was $\delta_{3}=56^{\circ}$, and the mining interval caving valid protective angle is $\delta_{4}=60^{\circ}$ (see Figure 7). When the trend mining length of the working face of No. $2_{1}$ coal seam is designed to be $500 \mathrm{~m}$, the mining trend length, $L$, of No. $1_{7}$ coal seam should be calculated according to the following formula: $\quad L=500+23.4 / \tan 56^{\circ}+23.4 / \tan 60^{\circ}=529.3 \mathrm{~m}$. Thus, when the trend length of the working face of No. $2_{1}$ 


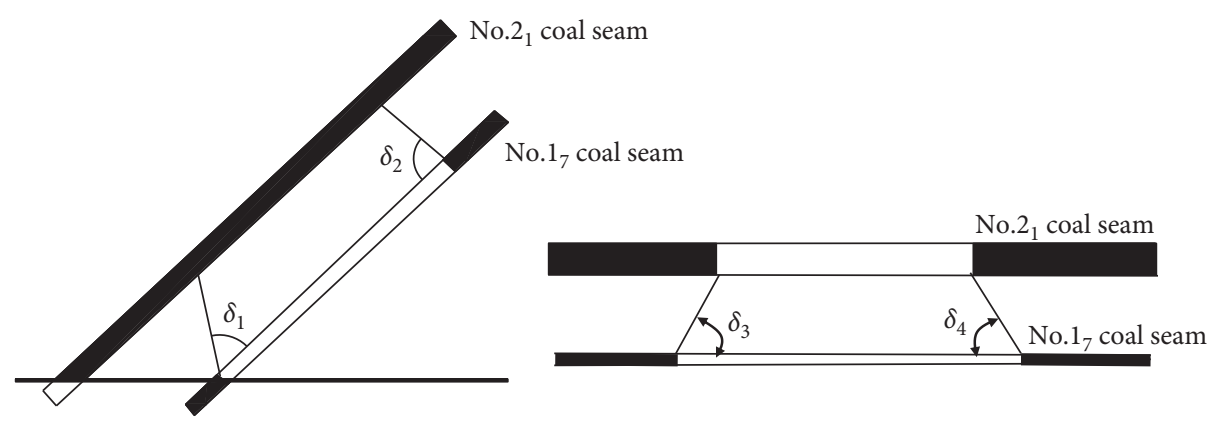

FIgURE 7: The mining pressure relief angle of the slanted direction and the trend direction.

coal seam is $500 \mathrm{~m}$, the mining trend length of No. $1_{7}$ coal seam must be larger than $529.3 \mathrm{~m}$.

4.2. Protective Seam Mining Principle of Prevention of Coal and Gas Outburst. After mining the protective seam, a free space will be formed in the rock mass, destroying the balance of the primary rock stress, redistributing the ground stress, moving the rock mass to the goaf, and resulting in phenomena including roof caving and sagging, chassis heaving, and so on [23-25]. The coal seam and the rock mass will undergo pressure relief and dilatation and lead to fractures of different sizes. The increase of the permeability coefficient will result in the increase of the gas flow. The gas emission will cause the decrease of the coal seam gas content, pressure, and potential. The gas emission enhances the coal mass strength. In other words, the antioutburst performance of the coal is intensified. Thus, it can be seen that the cause and basis of the serious of changes are the deformation and movement of the rock (coal) seam. The larger the deformation and movement are, the more adequate the pressure relief is and the better the protection effect is. The closer to the mining seam, the better the protective effect is; otherwise, the poorer it is. The protection effect is mainly decided by the mining geological and technical conditions.

To sum up, after mining the protective seam, the change order of the stress, deformation, gas, and the other parameters of the seam to be protected is shown as follows: first, the rock seam undergoes movement and deformation. The seam to be protected shows the pressure relief phenomenon. The ground stress of the coal seam decreases. The coal seam is inflated and deformed. The permeability of the coal seam is increased. With the gas desorption in the coal seam, the gas changes from the absorption state to the unbound state. With the increase of the borehole gas flow, the gas extraction amount increases, the coal seam gas pressure decreases, the coal seam gas content is reduced, and the mechanical strength of the coal seam is increased. All the above parametric changes suggest that the protection effect of the protective seam is the comprehensive function of pressure relief, permeability increase, and gas emission $[26,27]$. The pressure relief and permeability increase after the start of the protective seam mining plays the most important and decisive role in parametric changes. As long as the seam to be protected plays the role of pressure relief and permeability increase, the major parameters, including coal mass structure, gas pressure, gas content, and coal seam permeability, follow the above order. All these parametric changes will decrease or eliminate the coal seam outburst danger.

4.3. The Function of the Pressure Relief Gas Extraction. Detailed Rules of Coal and Gas Outburst Prevention and Control specifies that, "during the protective seam mining, the pressure relief gas of the seam to be protected shall be extracted as well." The thickness of the protective seam in Baoyushan Mine is $0.5 \mathrm{~m}$, and there is a hard $7.3 \mathrm{~m}$ thick limestone between seams, which would definitely cause unfavorable influence to the pressure relief and permeability increase effect of the overburden No. $2_{1}$ coal seam. In order to accelerate and expand the pressure relief and permeability increase function of the protective seam mining, the protective seam mining must extract the pressure relief gas of No. $2_{1}$ coal seam. Such extraction might further decrease the ground stress, increase the coal strength, and reach the goal of comprehensive prevention and control of outbursts.

\section{Movement and Deformation of the Overburden Coal Mass, Mining Fracture Development Characteristics of No. 2 Coal Seam, Pressure Relief Gas Migration Rule, and Gas Extraction Methods}

Since the mining thickness of No. $1_{7}$ coal seam is $0.5 \mathrm{~m}$, the average interlayer spacing between No. $1_{7}$ coal seam and No. $2_{1}$ coal seam is $23.4 \mathrm{~m}$, and there is a hard $7.3 \mathrm{~m}$ thick limestone in between, it is necessary to analyze and study the pressure relief and permeability increase effect of the overburden No. $2_{1}$ coal seam after mining No. $1_{7}$ coal seam, the movement and deformation of the overburden coal mass, the mining fracture development characteristics of No. $2_{1}$ coal seam, and the pressure relief gas migration rules. Based on the research findings, the corresponding gas extraction methods can be adopted.

5.1. Movement and Deformation of the Overburden Coal Mass, Fracture Development of No. $2_{1}$ Coal Seam, and Pressure Relief Gas Migration. Through the theoretical analysis and the field experiment, it was found that, during the mining process of No. $1_{7}$ coal seam, the whole overburden coal mass 
is bent, sagged, and deformed along with the hard limestone roof, but there is no craving zone formed. No. $2_{1}$ coal seam is located within the bent and sagged zone; thus, it cannot form a vertically smooth fracture with No. $1_{7}$ coal seam. Affected by mining No. $1_{7}$ coal seam, No. $2_{1}$ coal seam undergoes pressure relief and dilatational deformation. In No. $2_{1}$ coal seam, a lot of bedding fractures are formed. In the bedding direction, the permeability of No. $2_{1}$ coal seam is increased by a large margin.

Mining No. $1_{7}$ coal seam leads to the destruction of the balance state of the original stress of the overburden No. $2_{1}$ coal seam, and the deformation, movement, and fractures of the coal seam. As a result, the balance of the gas absorption and desorption will be destroyed, a lot of gas is turned from the absorption state to the free state, and the desorption gas of the coal mass expands to the fracture, leading to the dramatic increase of the gas concentration in the fractures. Thus, under the mining effect of No. $1_{7}$ coal seam, the migration conditions of the pressure relief gas, namely, "desorption $\longrightarrow$ diffusion $\longrightarrow$ transfusion," are formed.

Due to the dominant fracture distribution of bedding fracture in No. $2_{1}$ coal seam, the pressure relief gas has good bedding migration conditions. Therefore, the pressure relief gas in the protected seam only flows in the bedding fracture.

In order to effectively and evenly extract the gas in the protected seam during the migration active period of the pressure relief gas, it is necessary to create the conditions to enable the bedding migration and convergence of the pressure relief gas. Through the special extraction roadway of No. $2_{1}$ coal seam, the borehole was made for the extraction of the pressure relief gas. It can be seen that the gas is turned from the absorption state to the free state. Through the bedding separation fracture flow and the convergence in the borehole, and affected by the extraction negative pressure, a lot of pressure relief gas of No. $2_{1}$ coal seam is extracted.

It should be noticed that when No. $1_{7}$ coal seam is mined for a period of time, the overburden coal mass movement and deformation are gradually stabilized. The pressure relief effect exerted on No. $2_{1}$ coal seam gradually disappears, the permeability of the coal seam is reduced correspondingly, and the desorbed gas will be reabsorbed by the coal mass. Thus, it is necessary to extract the gas within the valid pressure relief period of No. $2_{1}$ coal seam and realize the goal of reducing the coal seam gas content and eliminating the coal seam outburst danger.

What is interesting in this study is that the overburden hard and extremely thick limestone roof sagged slowly but led to no craving zone. Now, let us focus on explaining this phenomenon. As the working face of No. $1_{7}$ coal seam is mined forward, the working face is directly overhanging. Because the immediate roof of No. $1_{7}$ coal seam is $L_{7}$ hard and extra-thick limestone roof, which is stable and not easy to collapse, there is no obvious movement and deformation of the overlying coal-rock mass in the early mining stage. As a large amount of coal is mined in the working face of No. $1_{7}$ coal seam, the hard and extra-thick limestone roof of $L_{7}$ begins to bend and sink slowly under the action of gravity of the overlying coal and rock mass. It can be seen that the overlying coal and rock mass produce the overall slow bending subsidence deformation, without falling zone and obvious fault zone, and No. $2_{1}$ coal seam is in the bending subsidence zone. There are separation cracks at the boundary of soft and hard strata of the overlying coal-rock mass, but there are few vertical fracture cracks. It can be seen from the field measurement that the gas pressure of No. $2_{1}$ coal seam drops gradually and slowly without sudden drop, which can also indicate that the roof is slowly sinking without caving phenomenon. The reason for these phenomena is that the mining height of No. $1_{7}$ coal seam is only $0.5 \mathrm{~m}$, and the roof of No. $1_{7}$ coal seam is very hard and extra-thick limestone roof. It is found that there are many bedding tensile fractures on the surface of No. $2_{1}$ coal seam, some of which have gone deep into the interior of the coal seam, while the number of vertical fracture fractures is few and not obvious. As the overlying strata are gradually compacted, the width and number of separation cracks between strata are reduced. A careful observation of No. $2_{1}$ coal seam shows that the coal seam is also gradually compacted and the width and number of bedding tensile cracks in the coal seam are obviously reduced.

5.2. Extraction Methods of the Pressure Relief Gas in No. $2_{1}$ Coal Seam. Concerning the actual mining geological conditions of Baoyushan Mine and in order to accelerate and expand the pressure relief and permeability increase function of No. $1_{7}$ coal seam, mining No. $1_{7}$ coal seam should extract the pressure relief gas of No. $2_{1}$ coal seam as well. During the mining process of No. $1_{7}$ coal seam, the pressure relief gas of the overburden No. $2_{1}$ coal seam has sound bedding migration conditions. The chassis grid drilling method can be adopted to extract the gas in the drill hole. To put it specifically, the method is to tunnel a special roadway for the gas extraction in the chassis rock seam; in the roadway, a drill site is dug at the interval of certain distance. Within the drill site, an upward drill hole is made in No. $2_{1}$ coal seam. The drill holes are evenly distributed in the coal seam in the form of grid. Relying on the pressure relief and permeability increase effect, the gas in No. $2_{1}$ coal seam is evenly and effectively extracted.

5.2.1. The Selection of the Special Gas Extraction Roadway. Concerning the practical geological conditions of Baoyushan Mine, No. $1_{7}$ coal seam roof is a layer of $7.3 \mathrm{~m}$ thick $L_{7}$ limestone. The upper part is a $2.6 \mathrm{~m}$ thick sandy mudstone, $11 \mathrm{~m}$ thick silty-fine sand, $2.5 \mathrm{~m}$ thick sandy mudstone, and $3.1 \mathrm{~m}$ thick No. $2_{1}$ coal seam. Therefore, the gas extraction roadway in the chassis should be conducted along the $L_{7}$ limestone roof. The distance from the extraction roadway to No. $2_{1}$ coal seam is maintained above $10 \mathrm{~m}$, and the roadway construction fracture surface is above $6 \mathrm{~m}^{2}$.

5.2.2. The Layout of the Cross-Layer Borehole for the Gas Extraction Roadway. A $5 \mathrm{~m}$ long extraction drill site perpendicular to the extraction roadway is set up every $20 \mathrm{~m}$. In the drill site, the borehole is made and the gas is extracted. Every drill site sets up a group of fan-shaped gas extraction 
boreholes. The borehole features a diameter of $91 \mathrm{~mm}$. Every drill site sets up seven cross-layer boreholes. The borehole space within the fully pressure relief area is $20 \mathrm{~m}$ and in the inadequate pressure relief area is $10 \mathrm{~m}$. The borehole spacing adopts the coal seam medium thickness as the standard. The two zones of the extraction roadways tunnel the connection roadway on the interior section and the end section. The fully negative pressure ventilation is formed. The gas extraction of the upward borehole on the grid is shown in Figure 8. All the extraction boreholes must finish their construction before mining No. $1_{7}$ coal seam. After the hole sealing, the gas extraction pipeline is switched on. After mining No. $1_{7}$ coal seam, the coal mass of No. $2_{1}$ coal seam undergoes dilatation, deformation, and pressure relief. The gas is thus activated. Under the join effect of the mine negative pressure and the coal seam gas pressure, the pressure relief gas is extracted. With the decrease of the coal seam gas content, the outburst danger of No. $2_{1}$ coal seam is eliminated.

5.2.3. Gas Extraction Devices. Two sets of 2BEC-40 gas extraction pumps are set up on the ground, whose exhaust capacity is $90 \mathrm{~m}^{3} / \mathrm{min}$. One is in use and the other stands by. The drilling devices feature the ZYG-150, 220, and 330 drill with the drill pipe having a diameter of $50 \mathrm{~mm} \sim 63 \mathrm{~mm}$ and a drill bit of $110 \mathrm{~mm}$ to make the boreholes for the gas extraction.

\section{The Pressure Relief, Permeability Increase, and Gas Extraction Effect after Mining the Extremely Thin Protective Seam}

The pressure relief and permeability increase effect of the protective seam is related to the interlayer spacing, the protective seam mining height, the interlayer lithology, and so on. Since No. $1_{7}$ coal seam thickness of Baoyushan Mine is just $0.5 \mathrm{~m}$, the interlayer space between No. $1_{7}$ and No. $2_{1}$ coal seam averages $23.4 \mathrm{~m}$, and there is a hard $7.3 \mathrm{~m}$ thick limestone in between, field inspection and experiment are needed to study the pressure relief and permeability increase of the overburden No. $2_{1}$ coal seam after mining No. $1_{7}$ coal seam. Two indexes, namely, coal seam pressure relief, and deformation and permeability changes, are adopted to directly reflect the pressure relief and permeability increase effect of the protective seam.

6.1. The Pressure Relief and Permeability Increase Effect of the Protective Seam. The permeability of the coal seam is an important parameter to reflect the difficulty degree of the gas migration and one of the feasible indexes to evaluate the gas extraction. It is also one of the indexes to judge the coal and gas outburst danger. The original coal mass permeability of No. $2_{1}$ coal seam is $0.0012 \mathrm{mD}$. After mining No. $1_{7}$ coal seam, No. $2_{1}$ coal seam undergoes pressure relief, dilatational deformation. The permeability of No. $2_{1}$ coal seam also undergoes corresponding changes. The permeability increases greatly. By comparing the permeability before and after the pressure relief of No. $2_{1}$ coal seam, an in-depth understanding of the changes of No. $2_{1}$ coal seam before and after the protective seam mining can be gained. Through the hole drill under the shaft, the actually measured permeability coefficient of No. $2_{1}$ coal seam after mining the protective seam is increased by about 400 times, about $0.4732 \mathrm{mD}$.

The permeability of coal seam increases by nearly 400 times, and the analysis reasons are as follows: in the process of mining No. $1_{7}$ coal seam, the overlying coal and rock mass gradually bends and sinks without caving zone and obvious fault zone. Due to the slow subsidence deformation of the overlying coal-rock mass, there are stratification fissures along the layers between different soft and hard rock strata, resulting in the expansion deformation of No. $2_{1}$ coal seam. A large number of bedding tensile fractures are produced in No. $2_{1}$ coal seam, so the permeability of the coal seam increases, and the pressure relief gas in No. $2_{1}$ coal seam flows along the bedding tensile fractures formed between layers. At this time, the pressure relief gas of No. $2_{1}$ coal seam must be strengthened to be extracted.

The site experiment suggests that, after mining No. $1_{7}$ coal seam, the roof and chassis of No. $2_{1}$ coal seam slowly sag along with the limestone. However, the sagging speed of No. $2_{1}$ coal seam chassis is more quick than that of the roof. In this way, No. $2{ }_{1}$ coal seam is stretched. In other words, the roof and chassis of No. $2_{1}$ coal seam undergo dilatational deformation. The relative deformation of the roof and chassis of No. $2_{1}$ coal seam obtained through the deep point method can be employed to reflect the pressure relief and permeability increase effect of No. $2_{1}$ coal seam. During the construction of deformation borehole, the borehole is required to enter the coal seam roof by $1.0 \mathrm{~m}$. A pair of steel wedges is installed on the roof and chassis of the coal seam to fix the deep points. The steel wedges are made up of steel pipes and steel plates, which look like inverted wedge-shaped rock bolt, but they are not solid inside. A reinforcing steel bar of about $10 \mathrm{~mm}$ thickness is welded to the steel wedge of the coal seam roof, which goes through the steel wedge of the coal seam chassis to the porthole. The steel wedge is welded with a seamless steel tube with a diameter of about $15 \mathrm{~mm}$, which is covered on the reinforcing steel bar connected with the steel wedge. The dial indicator and the micrometer calipers are used to measure the relative displacement of the steel pipe and the reinforcing steel bar. Then, the relative deformation of the coal seam roof and chassis is calculated. On 1\# borehole, the deep point method is used to test the dilatational deformation of the chassis and roof of No. $2_{1}$ coal seam. The coal thickness in $1 \#$ deformed hole is about $3.5 \mathrm{~m}$. The actually measured dilatation deformation is $72 \mathrm{~mm}$, and the maximum dilatational deformation ratio is $72 / 3,500=20.6 \%$. The maximum dilatational deformation is found in the $20 \mathrm{~m}$ of the working face. This suggests that the protective seam mining results in great reduction of the ground stress of No. $2_{1}$ coal seam. Due to the pressure relief, dilatational deformation of the coal seam within the coal layer to form the bedding fractures, it is beneficial for the migration of the pressure relief gas within the coal seam. The advance distance between the deformation of No. $2_{1}$ coal seam chassis and roof in 1\# borehole of No. 2 drill site and the working face of the protective seam is shown in Figure 9. 


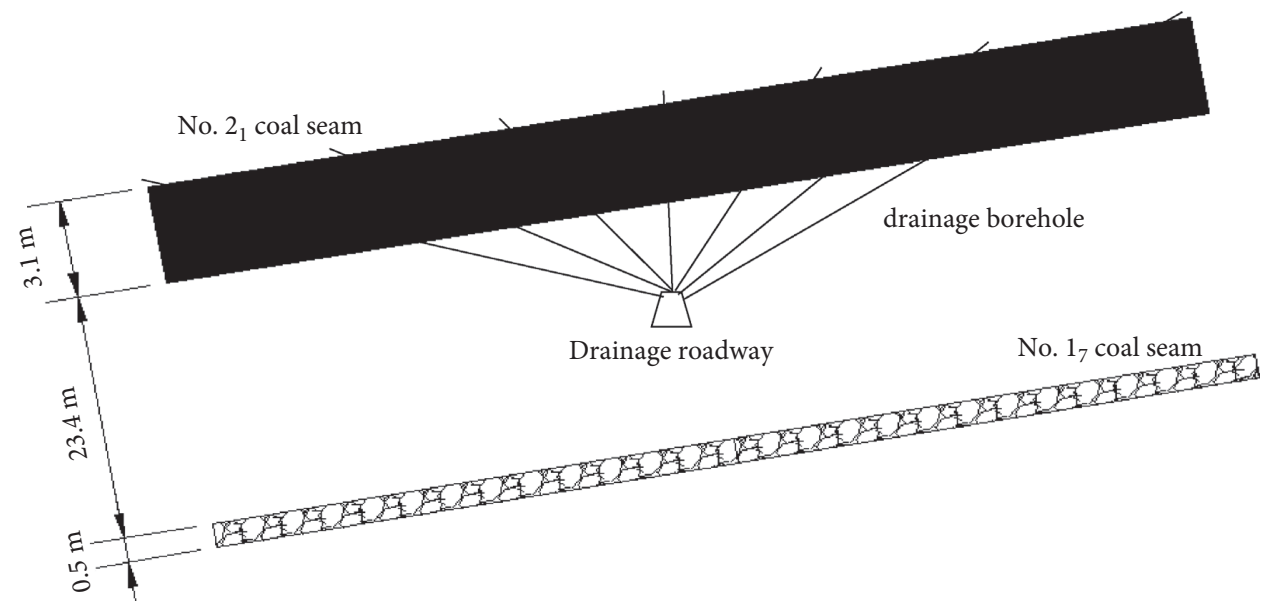

FIgURE 8: The layout of the drainage borehole for the drainage roadway.
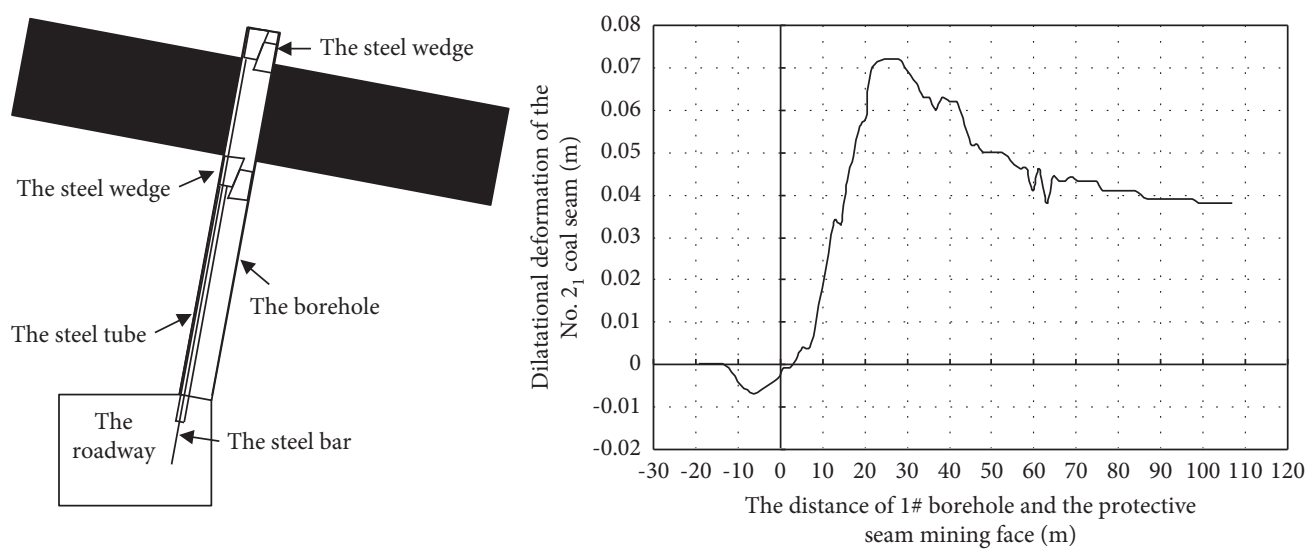

FIgURE 9: The dilatational deformation of No. $2_{1}$ coal seam.

Based on the analysis of Figure 9, the following conclusions can be drawn: (1) the protective seam mining has a great influence on the deformation of No. $2_{1}$ coal seam chassis and roof. With the progress of the protective seam mining, the deformation follows the change of compression, rapid dilatation, dilatational deformation reduction, and stabilization. In other words, the corresponding lower protective seam of No. $2_{1}$ coal seam is compressed by the upper coal mass before the mining. From the mining start line, the coal seam experiences compression stage and expansion stage. About $20 \mathrm{~m}$ above the mining start line, the dilatation and the deformation of No. $2_{1}$ coal seam reach the maximum. At the same time, the permeability of the coal seam increases dramatically. Within certain area, the dilatational deformation of No. $2_{1}$ coal seam tends to be stable. The area is called No. $2_{1}$ coal seam stable pressure relief and dilatation area. (2) The protective seam mining results in the redistribution of the stress of the overburden No. $2_{1}$ coal seam. The maximum compressive deformation of No. $2_{1}$ coal seam reaches $7 \mathrm{~mm}$. The maximum dilatational deformation of No. $2_{1}$ coal seam reaches $72 \mathrm{~m}$. (3) When No. $2_{1}$ coal seam is in a compressive deformation state, No. $2_{1}$ coal seam is in a pressure increase state, which might squeeze the free gas within the coal seam. The drill hole might be filled with the high concentration gas, but the gas amount is low. When the compressive deformation turns into the dilatational deformation, the coal seam will rapidly undergo pressure relief and permeability increase. The permeability will increase by a hundred times. The borehole will be filled with the high concentration gas, which will be emitted along with the pressure relief gas. It is the best time for the extraction of the pressure relief gas. With the increasing mining distance of the working face of the coal seam, since the overburden coal mass is formed and slowly sags, No. $2_{1}$ coal seam is gradually compacted and the dilatational deformation of No. $22_{1}$ coal seam gradually decreases. After reaching certain level, it will tend to be stable. At the moment, due to the gradual close of the fracture, the gas channels will be closed, the gas concentration within the borehole will rapidly decrease, and the gas amount will be reduced as well. This is the intermission for the gas extraction in the borehole. With the reduction of the remaining gas amount of No. $2_{1}$ coal seam and the significant reduction of the gas concentration and gas amount in the borehole, the extraction of the pressure relief gas is generally completed. 
TABLE 2: The investigated relief protective effect parameters of No. $2_{1}$ coal seam.

\begin{tabular}{|c|c|c|c|c|c|c|c|}
\hline \multicolumn{3}{|c|}{ Permeability coefficient (mD) } & \multicolumn{2}{|c|}{$\begin{array}{l}\text { Gas pressure } \\
\quad(\mathrm{MPa})\end{array}$} & \multirow{2}{*}{$\begin{array}{l}\text { Gas extraction } \\
\quad \text { rate }(\%)\end{array}$} & Gas content $\left(\mathrm{m}^{3} / \mathrm{t}\right)$ & \multirow{2}{*}{$\begin{array}{l}\text { Measured expansion displacement } \\
\text { of coal seam (mm) }\end{array}$} \\
\hline Original & $\begin{array}{l}\text { After } \\
\text { relief }\end{array}$ & $\begin{array}{l}\text { Additional } \\
\text { magnification }\end{array}$ & Original & $\begin{array}{l}\text { After } \\
\text { relief }\end{array}$ & & Original Remnant & \\
\hline 0.0012 & 0.473 & 394 & 1.17 & 0.12 & 68 & 9.74 & 72 \\
\hline
\end{tabular}

\subsection{The Gas Extraction Effect and the Outburst Elimination Field Verification}

6.2.1. Gas Extraction Effect. Currently, the gas extraction amount in the mine is about $30 \sim 35 \mathrm{~m}^{3} / \mathrm{min}$, the gas concentration is $33 \%$, the pure gas amount is $10 \sim 12 \mathrm{~m}^{3} / \mathrm{min}$, and the annual pure gas extraction amount reaches above 4 million $\mathrm{m}^{3}$. The gas extraction rate of the mine reaches $35 \sim 45 \%$. With the intensification of the gas extraction, the gas extraction rate increases correspondingly.

In this experiment, apart from the measurement of the original gas pressure and the gas content of No. $2_{1}$ coal seam, the remaining gas pressure and the gas content of No. $2_{1}$ coal seam after mining the protective seam are measured. Before mining the extremely thin protective seam, the maximum value of the gas pressure of No. $2_{1}$ coal seam reaches 1.17 MPa. The maximum gas content is about $9.73 \mathrm{~m}^{3} / \mathrm{t}$. After the combination of the extremely thin protective seam and the pressure relief gas extraction, the maximum remaining gas pressure of No. $2_{1}$ coal seam is $0.12 \mathrm{MPa}$, and the remaining gas content is $3.1 \mathrm{~m}^{3} / \mathrm{t}$. The pressure relief protective effect of No. $2_{1}$ coal seam after mining the extremely thin protective seam is listed in Table 2 .

In the process of the protective seam mining, the gas pressure of the drill hole decreases gradually, and no sharp drop occurs. Therefore, it can be deduced that there is no direct fracture between the goaf of the protective seam working face and No. $2_{1}$ coal seam. This also proves that, after mining the extremely thin protective seam working face, the overburden limestone roof sags gradually and shows no caving.

6.2.2. The Site Verification of the Outburst Elimination Effect. After the protective seam mining is combined with the pressure relief gas extraction, the blast capacity of No. $2_{1}$ coal seam mining working face is decreased from $950 \mathrm{~m}^{3} / \mathrm{min}$ to $500 \mathrm{~m}^{3} / \mathrm{min}$. The return air gas concentration of subroadway under the working face is decreased from the critical state to $0.3 \sim 0.5 \%$. The absolute gas emission quantity decreases from $8.5 \sim 10 \mathrm{~m}^{3} / \mathrm{min}$ to the current level of below $3 \mathrm{~m}^{3} / \mathrm{min}$. The absolute gas emission rate of the return air of the mining working face decreases by $70 \%$. During the production process, the gas never exceeds the limit, which well solves the problem of excessive gas and coal dust flying during the production process. The working face output is also increased by a large margin.

In the past, the tunneling of the roadway in No. $2_{1}$ coal seam without the mining protective seam was fulfilled by the $2^{*} 15 \mathrm{~kW}$ pivot axial flow fan. Under the condition of $300 \mathrm{~m}^{3} /$ min wind supply, the gas concentration of the return air reached above $0.6 \%$. During the gas emission period, the gas often exceeded the limit. The monthly footage should not exceed $50 \mathrm{~m}$. When the gas amount was high, the tunneling had to be stopped. Now, after the adoption of the mining protective seam, the gas concentration ranges within $0.15 \sim 0.3 \%$, when the tunneling is conducted in the protected roadway with the adoption of the $2^{*} 15 \mathrm{~kW}$ pivot axial flow fan and the wind supply of $200 \mathrm{~m}^{3} / \mathrm{min}$. The tunneling speed is increased from less than $50 \mathrm{~m}$ to about $120 \mathrm{~m}$ now, which not only eliminates the phenomenon of the excessive gas concentration and ensures the safe tunneling in the roadway of the mine but also alleviates the tension of production alternation and achieves good social and economic benefits.

\section{Conclusions}

(1) The actually measured gas pressure of No. $2_{1}$ coal seam of Baoyushan Mine in Dengfeng coalfield is 1.17 MPa, the gas content is $9.74 \mathrm{~m}^{3} / \mathrm{t}$, and the gas emission initial velocity is $12 \sim 27 \mathrm{mmHg}$. The original structure of the coal has been seriously damaged. The coal mass is filled with the block coal formed by the pressed pulverized coal. The strength is low and is fragile. It belongs to the full-thickness tectonic coal. The coal destruction type belongs to IV $\sim \mathrm{V}$ coal. The firmness coefficient of No. $2_{1}$ coal ranges within $0.1 \sim 0.18$. The permeability rate of the original coal seam is $0.0012 \mathrm{mD}$. The permeability of the coal seam is extremely poor. The parameters of No. $2_{1}$ coal seam gas outburst in Baoyushan Mine are far higher than the outburst critical indexes specified in Detailed Rules of Coal and Gas Outburst Prevention and Control, so the outburst danger is high and the coal and gas outburst dynamic disasters are very serious. According to the gas geological conditions of the Baoyushan Mine in Dengfeng coalfield, No. $1_{7}$ coal seam, being about $23.4 \mathrm{~m}$ under No. $2_{1}$ coal seam and having a thickness of $0.5 \mathrm{~m}$, is regarded as the lower protective seam for prior mining. At the same time, the special gas extraction roadway is set up in the chassis of No. $2_{1}$ coal seam. The borehole is made to extract the pressure relief gas of No. $2_{1}$ coal seam to achieve comprehensive treatment of the gas.

(2) During mining the extremely thin protective seam, the overburden coal and rock mass shows no caving zone. The whole overburden coal and rock mass bends, sags, and deforms along with the generation of the hard limestone roof. No. $2_{1}$ coal seam is located above the extremely thin protective seam roof and the bent sagging zone. Macroscopically speaking, there are no obvious cross-layer fractures, and a 
vertically smooth fracture cannot be formed between the extremely thin protective seams. Due to the function of the extremely thin protective seam, No. $2{ }_{1}$ coal seam undergoes pressure relief and dilatational deformation. Therefore, a lot of bedding fractures are formed in No. $2_{1}$ coal seam. The permeability of the coal seam along the bedding direction is increased by a large margin, while the permeability vertical to the bedding direction is relatively small. After No. $2_{1}$ coal seam obtains the pressure relief protection effect, the coal seam gas is desorbed. However, since a lot of bedding fractures are formed in the coal seam, the pressure relief gas in the coal seam flows along the bedding fractures. Concerning the distribution characteristics of the mining fractures of No. $2_{1}$ coal seam and the sound bedding migration conditions of the pressure relief gas, the gas extraction method is adopted in the borehole in the chassis.

(3) The field experiment results showed that, after mining No. $1_{7}$ coal seam, the permeability rate of No. 2 coal seam was increased by about 394 times, from $0.0012 \mathrm{mD}$ to $0.473 \mathrm{mD}$. After adopting the chassis grid borehole to extract the gas, the gas pressure of No. 21 coal seam decreased from $1.17 \mathrm{MPa}$ to $0.12 \mathrm{MPa}$. The gas content decreased from $9.74 \mathrm{~m}^{3} / \mathrm{t}$ to $3.1 \mathrm{~m}^{3} / \mathrm{t}$, which fully eliminates the coal and gas outburst dynamic disasters of No. $2_{1}$ coal seam and realizes the safe and effective mining of the mine.

(4) The adoption of No. $1_{7}$ as the protective seam in combination with the pressure relief gas extraction technique for the comprehensive treatment of No. $2_{1}$ coal seam can eliminate the problem threatening the safe production of the mine. The gas concentration of the return air of No. $2_{1}$ coal seam working face is maintained within $0.3 \% \sim 0.4 \%$, which wipes out the phenomenon of excessive gas and achieves significant results for the gas treatment. In this way, the high gas outburst coal seam can be mined safely under the low gas state, and the mine achieves significant economic and safety benefits [28, 29].

\section{Data Availability}

The data used to support the findings of this study are available from the corresponding author upon request.

\section{Conflicts of Interest}

The authors declare that they have no conflicts of interest.

\section{References}

[1] B. P. Plc, BP Statistical Review of World Energy, 2010.

[2] C. Cattaneo, M. Manera, and E. Scarpa, "Industrial coal demand in China: a provincial analysis," Resource and Energy Economics, vol. 33, no. 1, pp. 12-35, 2011.

[3] L. Wang and Y.-P. Cheng, "Drainage and utilization of Chinese coal mine methane with a coal-methane co- exploitation model: analysis and projections," Resources Policy, vol. 37, no. 3, pp. 315-321, 2012a.

[4] Y. P. Cheng, Mine Gas hazard Control Theory and Engineering Application, China university of mining and technology press, Beijing, China, 2010.

[5] S. Xue, Y. Wang, J. Xie, and G. Wang, "A coupled approach to simulate initiation of outbursts of coal and gas - model development," International Journal of Coal Geology, vol. 86, no. 2-3, pp. 222-230, 2011.

[6] Y. P. Cheng, L. Wang, and X. L. Zhang, "Environmental impact of coal mine methane emissions and responding strategies in China," International Journal of Greenhouse Gas Control, vol. 5, no. 1, pp. 157-166, 2011.

[7] L. Wang, Y. P. Cheng, L. Wang, P. K. Guo, and W. Li, "Safety line method for the prediction of deep coal-seam gas pressure and its application in coal mines," Safety Science, vol. 50, no. 3, pp. 523-529, $2012 b$.

[8] Y. P. Cheng, Q. X. Yu, and L. Yuan, "Experimental research of safe and high-efficient exploitation of coal and pressure relief gas in long distance," China University of Mining and Technology, vol. 33, pp. 132-136, 2004.

[9] M. Tu, N. B. Huang, and B. A. Liu, "Researchon pressure-relief effect of overlying coal rock body using far distance lower protective seam exploitation method," Mining and Safety Engineering, vol. 24, pp. 418-426, 2007.

[10] L. Wang, Y. P. Cheng, F. R. Li, H. F. Wang, and H. B. Liu, "Fracture evolution and pressure relief gas drainage from distant protected coal seams under an extremely thick key stratum," Journal of China University of Mining and Technology, vol. 18, no. 2, pp. 182-186, 2008.

[11] L. Yuan, "Research on gas drainage technology for seam group with complicated and difficult conditions," Coal Science and Technology, vol. 31, pp. 1-4, 2003.

[12] J. Brandt and R. Sdunowski, "Gas drainage in high efficiency workings in German Coal mines," in Proceedings of the 2007 China (Huainan) International Symposium on Coal Gas Control Technology, pp. 22-29, China university of mining and technology press, Huainan, China, 2007.

[13] Y. P. Cheng, J. H. Fu, and Q. X. Yu, "Development of gas extraction technology in coal mines of China," Mining and Safety Engineering, vol. 26, pp. 127-139, 2009.

[14] T. B. L. Daniel, B. Alireza, N. Chikezie, and A. W. David, "A review of Australia's natural gas resources and their exploitation," Journal of Natural Gas and Science Engineering, vol. 10, pp. 68-88, 2013.

[15] L. Ying-ke, Z. Fu-bao, L. Lang, L. Chun, and H. Shen-yong, "An experimental and numerical investigation on the deformation of overlying coal seams above double-seam extraction for controlling coal mine methane emissions," International Journal of Coal Geology, vol. 87, pp. 139-149, 2011.

[16] Q. X. Yu, Y. P. Cheng, C. L. Jiang, and S. -N. Zhou, "Principles and applications of exploitation of coal and pressure relief gas in thick and high-gas seams," China University of Mining and Technology, vol. 33, pp. 127-131, 2004.

[17] H. Liu, H. Liu, and Y. Cheng, "The elimination of coal and gas outburst disasters by ultrathin protective seam drilling combined with stress-relief gas drainage in Xinggong coalfield," Journal of Natural Gas Science and Engineering, vol. 21, pp. 837-844, 2014.

[18] P. D. William and J. S. Steven, "Measuring the gas content of coal: a review," International Journal of Coal Geology, vol. 35, pp. 311-331, 1998. 
[19] X. He, W. Chen, B. Nie, and M. Zhang, "Classification technique for danger classes of coal and gas outburst in deep coal minesfication technique for danger classes of coal and gas outburst in deep coal mines," Safety Science, vol. 48, no. 2, pp. 173-178, 2010.

[20] L. Liu, Y. P. Cheng, H. F. Wang, L. Wang, and X. Q. Ma, "Principle and engineering application of pressure relief gas drainage in low permeability outburst coal seam," Mining Science and Technology, vol. 19, no. 3, pp. 342-345, 2009.

[21] T. Xu, C. A. Tang, T. H. Yang, W. C. Zhu, and J. Liu, "Numerical investigation of coal and gas outbursts in underground collieries," International Journal of Rock Mechanics and Mining Sciences, vol. 43, no. 6, pp. 905-919, 2006.

[22] R. L. Zhang and I. S. Lowndes, "The application of a coupled artificial neural network and fault tree analysis model to predict coal and gas outbursts," International Journal of Coal Geology, vol. 84, pp. 141-152, 2010.

[23] H. Guo, L. Yuan, B. Shen, Q. Qu, and J. Xue, "Mining-induced strata stress changes, fractures and gas flow dynamics in multi-seam longwall miningflow dynamics in multi seam longwall mining," International Journal of Rock Mechanics and Mining Sciences, vol. 54, pp. 129-139, 2012.

[24] W. Yang, B. Q. Lin, Y. A. Qu et al., "Mechanism of strata deformation under protective seam and its application for relieved methane control," International Journal of Coal Geology, vol. 85, no. 3-4, pp. 300-306, 2011 a.

[25] W. Yang, B. Q. Lin, Y. Q. Qu et al., "Stress evolution with time and space during mining of a coal seam," International Journal of Rock Mechanics and Mining Sciences, vol. 48, no. 7, pp. 1145-1152, 2011b.

[26] M. B. A. Díaz and C. N. González, "Control and prevention of gas outbursts in coal mines, Riosa-Olloniego coalfield, Spainfild, Spain," International Journal of Coal Geology, vol. 69, no. 4, pp. 253-266, 2007.

[27] K. Noack, "Control of gas emissions in underground coal mines," International Journal of Coal Geology, vol. 35, no. 1-4, pp. 57-82, 1998.

[28] China State Administration of Work Safety, Detailed Rules of Coal and Gas Outburst Prevention and Control, China Coal Industry Press, Beijing, China, 2019.

[29] State administration of work safety (SAWS), Protective Mining Technical Specifications. AQ 1050-2008, China Coal Industry Publishing House, Beijing, China, 2008. 